\title{
Los primeros libros de fútbol publicados en España (1900-1919)
}

\author{
Xavier TORREBADELLA-FLIX \\ Universidad Autónoma de Barcelona \\ xtorreba@gmail.com \\ Antoni NOMDEDEU-RULL \\ Universitat Rovira i Virgili \\ antonio.nomdedeu@urv.cat
}

Recibido: Diciembre 2014

Aceptado: Febrero 2015

\begin{abstract}
Resumen: Este artículo tiene como objetivo exponer cronológicamente la bibliografía en torno al fútbol publicada en España en las dos primeras décadas del siglo XX con el propósito de validar su contribución al nacimiento e implantación de este deporte en España. El estudio se establece a través del uso de recursos y técnicas de análisis histórico relativo al tratamiento de las fuentes documentales originales. Los resultados obtenidos revelan que, en los orígenes e implantación del fútbol en España durante las dos primeras décadas del siglo XX, las publicaciones especializadas sobre este deporte representaron una ineludible referencia entre los primeros aficionados para dar a conocer y poder desarrollar los fundamentos técnicos del juego. Aunque la literatura futbolística fue escasa y criticada por su simplicidad técnica, prestó un útil servicio a cuantos neófitos trataron de iniciarse en el popular deporte inglés. Asimismo, el fútbol generó la bibliografía más importante del movimiento gimnástico-deportivo de principios del siglo XX; una bibliografía que hoy nos ayuda a interpretar el desarrollo del fútbol español.
\end{abstract}

Palabras clave: Bibliografía del fútbol; Documentación deportiva; Historia del deporte español; Historia del fútbol.

\section{The first football books published in Spain (1900-1919) ${ }^{1}$}

\begin{abstract}
This article aims to chronologically expose around football literature published in Spain in the first two decades of the twentieth century in order to validate its contribution to the creation and implementation of this sport in Spain. The study is developed through the use of resources and techniques of historical analysis about the treatment of the original documentary sources. The results show that, at the origins and implementation of football in Spain during the first two decades of the twentieth century, the specialized publishing around this sport represented an essential reference among the first fans to raise awareness and to develop the

\footnotetext{
${ }^{1}$ Este estudio se inserta en el marco de la ayuda concedida por la URV (“Ajuts per fomentar la incorporació i visualització d'investigadors emergents a la Universitat Rovira i Virgili Banco Santander 2013 (LINE2013)”) por el proyecto: "Diccionario histórico de términos del fútbol (fase inicial)” (Ref. 2013LINE-04) (desde 01/07/2013 hasta 31/12/2014).
} 
technical fundamentals of the game. Although football literature was limited and criticized due to its technical simplicity, it provided a valuable service to all the neophytes who tried to get started in this popular English sport. Likewise, football generated the most important literature of the gymnastic-sports movement of the early twentieth century, which helps us today to interpret the development of Spanish football.

Keywords: Football history; Football literature; History of Spanish sport; Sports documentation.

\section{INTRODUCCIÓN}

El poco apego científico en España para revisar la historia del deporte es preocupante, pues en esta materia se evidencia un atraso muy considerable con respecto a otros países. Por un lado, existe una abundante producción literaria referente a la historia del fútbol, pero las publicaciones se circunscriben a ambientes locales y regionales. Por otro lado, se encuentra también una gran cantidad de obras en el ámbito del asociacionismo privado, pero que se concreta en las historias de los clubes. En la mayoría de estos trabajos se descubre una narración descriptiva de los hechos envueltos de un romanismo característico que inunda frecuentemente la historia del deporte. Disponemos, pues, de pocas obras importantes para cubrir una historia social del fútbol en España (Díaz, 2000; McFarland, 2004, 2012, 2013; Moscoso y Alonso, 2005; Pujadas y Santacana, 2001; Uría, 2008a , 2008b; Simón, 2011, 2012). No obstante, destacamos en este estudio otros trabajos generales sobre la historia del deporte en España que contribuyen a una mejor contextualización e interpretación, pese a que no profundizan en el fútbol (Almeida, 2006; Domínguez, 2009; Pujadas 2011; Pujadas y Santacana 1995, 1997, 2001; Rivero, 2003; Sanchís, 2010; Sirera, 2008).

En el caso concreto de este deporte, la bibliografía existente sobre el tema que nos ocupa, con las aportaciones recientes de Bahamonde (2002), Bálmont (2007, 2009), Castro (1912), Turuzeta (2012), Torrebadella (2012c) y otras más que se centran en los orígenes y desarrollo del fútbol, demuestra que las discusiones historicistas se hallan en una fase todavía inicial.

La amplia documentación actual puesta al descubierto en Internet por parte de instituciones y particulares deben servir para proporcionar estudios de base y para completar y mejorar las investigaciones existentes de la historia social del deporte (Torrebadella y Nomdedeu, 2014). En este campo debiera tener una especial atención el fútbol, puesto que cada vez contamos con más documentos debido al interés romántico que despierta el estudio histórico y social de este deporte. Es pues el fútbol un deporte del que poco sabemos de él, a pesar de que genera todo tipo de documentación bibliográfica,. En esta dirección se presenta desde hace unos años Cuadernos del Fútbol, una firme apuesta para construir y legitimar una historia del fútbol en España. 
La elaboración de una historia social de los orígenes y el desarrollo del fútbol en España es todavía una asignatura pendiente. A este respecto, estudios fenomenológicos, estructuralistas, constructivistas o posiciones críticas o deconstructivas deben pues alumbrar este nuevo espacio de investigación que aún está por construir.

El estudio inédito que aquí presentamos tiene como objetivo exponer cronológicamente la bibliografía en torno al fútbol publicada en España en las dos primeras décadas del siglo XX para, de este modo, reconocer su contribución al nacimiento e implantación de este deporte en España. Para ello, partimos de la suposición según la cual la literatura técnica y periodística especializada acerca del fútbol fue una referencia ineludible para complementar el nacimiento e implantación de este deporte. En otras palabras, estas obras sirvieron a los deportistas neófitos y a otros aficionados para conocer y desarrollar el juego. Los trabajos que la conforman son fruto, por un lado, de la labor de recopilación realizada en trabajos anteriores sobre el estudio de la bibliografía deportiva publicada en España entre 1900 a 1939 (Torrebadella, 2009, 2011 ${ }^{\text {a; }}$ Torrebadella y Nomdedeu, 2014). La mayor parte de la contextualización histórica se desarrolla a partir de las informaciones que aportan los mismos libros, ampliadas y reforzadas con datos de la prensa deportiva de la época. Este enfoque es una genuina aportación inédita en la historiografía del fútbol en España ya que tiende a sufragar una visión de conjunto en el panorama nacional, estudio que todavía no tiene precedentes. Asimismo, para consolidar el estudio, hemos revisado y atendido, por otro lado, otros recientes trabajos de investigación (entre otros, los estudios de Lagardera, 1992; Otero 2003; Bahamonde, 2002, 2011; Almeida, 2006; Bálmont, 2007, 2009; Domínguez, 2009; Pujadas, 2011; Simón 2011; Castro, 2012; McFarland, 2012, 2013) que han contribuido a esclarecer en estos últimos años la interpretación histórica del fútbol en España.

La contextualización del marco teórico histórico se ha organizado a partir de la consideración de dos etapas o períodos claramente identificados: la etapa de gestación burguesa (1900-1909) y la etapa de consolidación institucional (19101919). La primera etapa se caracterizó por el desarrollo que protagonizó el fútbol con la participación de la sociedad burguesa de la primera década del siglo XX, período en el que se inició un proceso de institucionalización de las estructuras organizativas de este deporte. En la segunda etapa, y coincidiendo con la segunda década del siglo $\mathrm{XX}$, se produjo la consolidación del proceso de institucionalización, aspecto que favoreció su expansión y el acceso inicial de una participación menos elitista y popular.

\section{MÉTODO}

Para elaborar la bibliografía relativa al fútbol publicada en España en las dos primeras décadas del siglo XX, se han utilizado recursos y técnicas de análisis 
histórico sobre el tratamiento de las fuentes documentales originales. El primer recurso ha tratado la aplicación pertinente a la fundamentación heurística acerca de la búsqueda de fuentes documentales cercanas al período objeto de estudio, entre 1900 y 1919. Para ello se han aprovechado, esencialmente, las aportaciones bibliográficas de Torrebadella (2009, 2011 a 2012c) y Torrebadella y Nomdedeu (2013, 2014) en torno a la educación física, el deporte y el fútbol, por un lado, y la localización de las obras en los fondos documentales, como la Biblioteca de l'Esport (Barcelona), por el otro. En segundo lugar, se ha procedido al análisis crítico de las obras -aproximación hermenéutica- y al vaciado de los contenidos que nos permitieran describir la configuración del panorama que se iba conformando sobre los primeros libros de fútbol publicados en España.

También se han considerado otras fuentes secundarias con respecto al objeto de estudio (Bahamonde, 2002, 2011; Castro, 2012; García-Castell, 1968; Polo, 1986; Torrebadella, 2012c). La revisión de estos trabajos historicistas ha permitido la aproximación contextual necesaria para fijar el marco teórico histórico. Estos estudios también han facilitado el análisis y discusión de las fuentes históricas.

Este proceso de tratamiento de las fuentes documentales ha permitido fijar la coherencia en el análisis de las informaciones, redactar la interpretación de sucesos, presentar datos y resultados concluyentes y sentar las bases para poder formular su discusión.

\section{CONTEXTUALIZACIÓN DEL MARCO HISTÓRICO}

Hemos dividido el periodo que va de 1900 a 1919, que en otro estudio (Torrebadella y Nomdedeu, 2014) hemos denominado Etapa de gestación o regeneracionista, en dos etapas claramente diferenciadas: Etapa de gestación burguesa (1900-1909) y Etapa de consolidación institucional (1910-1919). Esta división coincide con importantes momentos y períodos históricos que conllevaron cambios políticos, sociales y económicos significativos. El impacto de estas transformaciones también repercutió en el desarrollo social del deporte y tuvo su reflejo en la presencia de la literatura deportiva relativa al fútbol.

\subsection{ETAPA DE GESTACIÓN BURGUESA (1900-1909). EL FÚTBOL ANTE EL REGENERACIONISMO, LA MODA Y LA EDUCACIÓN FÍSICA}

A lo largo de la primera década del siglo XIX, el fútbol aún se practicaba como un deporte fundamentalmente atlético y amateur. Los jóvenes que jugaban al fútbol también lo compatibilizaban con otros deportes y rendían culto a la educación física. Eran conocidos como sportsmen y solían ser representantes de la burguesía que emulaban las modas o costumbres de la colonia anglosajona, 
frecuentemente establecida en zonas de desarrollo industrial (Castro, 2012; Polo, 1986; Torrebadella, 2012c).

A principios del siglo pasado, Antonio Viada (1903: 15) se lamentó del poco apego de los españoles al desarrollo deportivo. Citaba como hecho anacrónico que el deporte estaba mucho más desarrollado en Europa que en España, donde era prácticamente desconocido: “¿A qué es debida esta resistencia del público español a la vida sportiva? Porque hay que tener presente que el sport en nuestro país existe con excepción; no ha entrado en las costumbres”. Viada (1903: 485) indicaba que el juego del foot-ball ya estaba "bastante extendido en ciertas provincias especialmente en la región catalana, existiendo sólo en Barcelona más de veinte clubs”. A finales de 1902 se creó oficialmente la Asociación de Clubs de Foot-ball de Barcelona que demostraba el extraordinario desarrollo que el fútbol estaba alcanzando en esta ciudad (Asociación de clubs de Foot-ball de Barcelona, 1903; Torrebadella, 2012c). En esta época en Barcelona se disputaban competiciones como la Copa Macaya y el concurso organizado por la Federación Gimnástica Española (1902). Indispensablemente, pues, se hacía necesaria la presencia y divulgación de una fáctica reglamentación del juego, como así sucedió con el que consideramos fue el primer Reglamento de foot-ball publicado en España, precisamente promovido por la Asociación de Clubs de Foot-ball de Barcelona (1902).

Como considera Lagardera (1996), Barcelona se identificó como la principal divulgadora del fútbol y del deporte en general en España. Así lo atestiguan los proyectos que extendieron su radio de acción fuera de Cataluña. Un claro ejemplo de ello lo constituyeron las publicaciones Los Deportes (1897-1910), El Mundo Deportivo (1906) y una incipiente bibliografía especializada, en la que el fútbol tomaba la iniciativa por delante de otros deportes. En esta época, el fútbol era un deporte elitista vinculado a los jóvenes de las clases más acomodadas (Castro, 2012; Lagardera, 1990; Otero, 2003). Fuera de Cataluña, el fútbol se desarrollaba principalmente en Madrid, en las principales ciudades portuarias del Norte de España, como en Bilbao, Vigo, La Coruña o Gijón, además de Oviedo (Soto, 1930) y en el Sur de la Península Ibérica, en poblaciones como Jerez de la Frontera, Huelva o Sevilla (Castro, 2012).

A finales de 1902, en Madrid se encabezaban iniciativas para constituir una Federación Española de Clubes de Foot-ball, pero los intentos terminaron únicamente en la constitución de la Asociación Madrileña de Foot-ball, que presidió Carlos Padrós. De igual modo, se había pedido al Rey de España de entonces, Alfonso XIII, el obsequio de una copa para disputar el campeonato de España cada año entre las sociedades constituidas. En esta época, en Madrid existían 5 clubes -Madrid FC, New, Español, Moncloa y Retiro (L. Z. 1902)- y el fútbol, a diferencia de Barcelona, lo practicaban fundamentalmente aristócratas y miembros de la alta burguesía. Sirvan de ejemplo los tres casos siguientes. Los partidos del Madrid Foot-ball Club tenían lugar en el Hipódromo, en donde asistían representantes de la alta sociedad, inclusive S. M. el Rey (Partido de foot- 
ball en el Hipódromo, 1902). En la capital, la revista Gran Vida (1903-1935) ofreció cobertura publicista al nuevo deporte, que si bien mantuvo principalmente una posición de desventaja con respecto a otros aristocráticos deportes, en pocos años su presencia aumentó de forma considerable (Otero, 2003). En 1903 la Asociación Madrileña de Foot-ball organizó el llamado "concurso de seriesPremio Codorniu" - primer campeonato de Madrid de clubes- donde se disputaba un premio de la casa Codorniu, que consistía en cuatro cajas del famoso cava catalán (Foot-ball, 1903).

A falta de un manual de foot-ball, la revista Los Deportes, que tenía un alcance nacional, incorporaba artículos que trataban de ilustrar los aspectos técnicos del juego, como, por ejemplo, los publicados por "Un delantero" -pseudónimo de Luis de Ossó, secretario del Foot-ball Club Barcelona- (García-Castell, 1968: 37). En Madrid, la elegante revista Gran Vida también trataba de divulgar las reglas y las técnicas del juego (Foot-ball. El arte de defender la meta, 1903; Vicente de Castro, 1904). En poco menos de un año, ya se habían doblado los clubes de la capital: Madrid FC, Hispania FC, Moderno FC, Victoria FC, Retiro FC, Nuevo FC, Internacional FC, Moncloa FC y Sport FC (Meléndez, 1903). Vicente de Castro (1904: 10) citaba que el foot-ball, dentro de poco, "habrá oscurecido a nuestra pelota y vendrá a ser el verdadero juego nacional”. Sin embargo, en 1906 disputaban el campeonato de Madrid solamente cuatro equipos: el Madrid FC, Iris, Moncloa y Athlétic (Foot-ball, 1906). Con todo, en la capital de España el fútbol no adquiría el carácter popular que estaba alcanzando en Cataluña. Sirva de ejemplo que una entidad tan emblemática como la Sociedad Gimnástica Española no organizó su primer equipo de fútbol hasta 1908, veintiún años después desde su fundación (Gómez, 1914).

Como indica Lagardera (1992), la ley del descanso dominical de 1904 marcó una inflexión positiva en el asociacionismo deportivo. La prensa de Madrid reconocía que el deporte estaba alcanzando un rápido desarrollo al comprobar cómo también la población de Manzanares había creado un Club de Foot-ball. Precisamente, el fútbol venía a ejemplarizar con su práctica el discurso regeneracionista de la época, pues como citaba Luis Lozano (1905: 3), redactor de las "Notas de Sport” de El Liberal, "para la regeneración de un país lo primero es criar hombres, y cultivando los sports es como se consiguen hombres fuertes, ágiles y vigorosos".

En 1905 se creó en Madrid una primera Federación Española de Foot-ball (Ribes, 1928; Soto, 1930; Valserra, 1944) que, a pesar de lo novedoso de la iniciativa, no fue suficientemente apreciada por parte de los protagonistas de la época. Desde El Mundo Deportivo y la Asociación de Foot-ball de Barcelona, se estaba liderando una propuesta para unir todo el fútbol español en una única Federación (Mensa, 1909a; Steimberg, 1906a , 1906b). En 1906, estaba en preparación el Manual del foot-ballista español -una obra no localizada- de Miguel Sena, futbolista del Club Ciclista de San Sebastián y corresponsal de $E l$ 
Mundo Deportivo en San Sebastián, que decía contener, además de las reglas del fútbol, "muchos consejos a los aficionados y clubs que quieren implantar el football. También contendrá la lista completa de las entidades de foot-ball en España" (Foot-ball, 1906: 5). Este mismo año, Los Deportes colaboraba con la Asociación de clubs de Foot-ball de Barcelona en la publicación de un reglamento del juego a cargo de Isidro Lloret (1906).

Sin embargo, como declaraba Alberto Serra (1906 $)$, al ocuparse de considerar la idoneidad de incorporar el fútbol en los colegios, la forma de jugar de la mayoría de los equipos no tenía la limpieza y la elegancia del juego que desplegaban los equipos extranjeros. Serra afirmaba que apenas se conocían las normas del fútbol y las estrategias del juego, aspecto que impedía disputar partidos que agradaran al público. Esta opinión coincidía con la Gamper (1914) cuando citaba, a partir del conocimiento del reglamento y después de haber practicado el fútbol varios años, que la forma de jugar de los españoles distaba mucho de la de los equipos extranjeros.

En esta época El Mundo Deportivo, dirigido por Narciso Masferrer, se presentó como el segundo periódico especializado de ámbito nacional del deporte. En relación con la visita del Madrid FC a Barcelona y la labor de Carlos Padrós que tanto hacía por la promoción del fútbol en España, Alberto Serra (1906b: 3) recordaba que podrían ser muchas las regiones de que sin "vida y pujanza deportiva, podrían ser objeto de enérgica regeneración con la implantación de este emocionante ejercicio atlético".

En 1907 se constituía en Barcelona la Federación Catalana de Clubs de Football, formada por trece clubes y presidida por Isidro Lloret Masaguer, presidente del X Sporting Club (Navarro, 1917) y redactor de la sección de Foot-ball en Los Deportes. En este año, en el Campeonato de España de Clubes de Foot-ball, que venía celebrándose en Madrid desde 1902, participaban solo los equipos de Huelva, Barcelona -se retiró-, Bilbao, Salamanca, Madrid y Vigo (Alonso, 1924).

Podemos sostener que, antes de llegar a la primera década del siglo XX, el fútbol ya se practicaba en todas las ciudades de España y que, aparte de Barcelona y Madrid, en algunas regiones del Norte ya se disputaban campeonatos regionales. Uno de estos era el Concurso regional de Vigo en el que en 1908 ya participaban siete equipos (Corresponsal, 1908). A primeros de 1910, Huelva acogió los partidos de El Campeonato de Foot-Ball de Andalucía y Extremadura (1910), entre las sociedades Balón-Pie y Sociedad de Foot-Ball de Sevilla y el Huelva Recreation Club de Huelva.

Un Sportman (1909), haciéndose eco de la afición de los jóvenes pamploneses a este nuevo sport, en tiempos, según señalaba, de la "anglomanía”, ponía énfasis en explicar cuál era la forma de jugar el foot-ball que se practicaba en Pamplona y en diferenciarlo del Rugby. Asimismo, receloso de las modas extranjeras, recordaba el juego español llamado "caput-chaca”, que no era más que una rudimentaria forma de jugar al foot-ball. De aquí se originó el refrán de "no dar 
pie con bolo"² (Un Sportman, 1909: 1). Esta animadversión a los juegos extranjeros y en especial, como recordaba Gamper (1914), al foot-ball, fue uno de los obstáculos que impidieron franquear la línea de la popularidad. Pero, además, hubo otros inconvenientes, como la excesiva violencia de su práctica, que también estaba asociada al desconocimiento de las reglas y técnicas del juego, y la falta de terrenos públicos en los que poder practicar el nuevo deporte.

En esta época se desató una genuina discusión terminológica liderada por Mariano de Cavia para "españolizar" el lenguaje deportivo anglosajón; en particular, propuso sustituir la palabra foot-ball por el calco lingüístico balompié (Torrebadella y Nomdedeu, 2013). De poco valieron las voces que reclamaban el balompié, pues el 14 de octubre de 1909 se creó en Madrid, por segunda vez, la Federación Española de Foot-ball (Polo, 1986) constituida por 25 entidades que representaban las poblaciones de Alicante, Barcelona, Cartagena, Coruña, Escorial, Guipúzcoa, Huelva, Madrid, Navarra, Santander, Tarragona, Toledo, Valencia, Vigo (Ya tenemos Federación, 1909). Esta primera Federación no agrupó a todos los clubes, quedando fuera de ella algunos importantes como el Athlétic Club de Bilbao o el Madrid FC (Mensa, 1909b). Ello provocó durante varios años controversias, escisiones y la celebración de varias competiciones que los clubes disputaban por separado.

El fútbol llegó también a la Academia de Infantería “fomentando así el desarrollo de este higiénico ejercicio que ha de contribuir a la regeneración de nuestra raza en el porvenir” (M., 1907: 220). De igual modo, Julio del Castillo (1909) lo incorporó en La educación física del soldado como uno de los medios de preparación física militar. Destacaba el foot-ball o "balompié” como así lo habían considerado en las escuelas militares en Francia.

Desde Santander se citaba que las prácticas del fútbol en el Regimiento de Valencia núm. 23, dirigidas por el oficial Quirós, habían realizado grandes beneficios físicos a los reclutas. Por ello se deseaba la extensión de dicha práctica a todo el ejército español: “¿Por qué no hacemos que cada soldado sea un deportista?” (J. D. V., 1910: LXXII).

En Barcelona el fútbol infantil o escolar alcanzó muy pronto elevadas cotas de participación, situación que condujo a la Federación Catalana de Clubs Fútbol, que dirigía Albert Serra Guixà, a la organización del primer Campeonato de Fútbol Infantil de Cataluña (Campeonato infantil, 1910). Como colofón final de este

\footnotetext{
${ }^{2}$ El Diccionario de la lengua española de la Real Academia Española no recoge esta expresión, sí en cambio no dar pie con bola con el significado de "Hacer mal las cosas por ignorancia o aturdimiento". Asimismo, no dar pie con bolo no se documenta en el Corpus diacrónico del español de la misma institución, mientras que se hallan 46 casos en 34 documentos, de los siglos XVI, XVII, XIX y XX. [Fecha de consulta: 5 de junio de 2014]. Este dato demuestra la necesidad de describir lingüísticamente las fuentes documentales analizadas de cara a la obtención de una mejor descripción del léxico espeñol en general y el del fútbol en particular.
} 
período, destaca el artículo de José Elías Juncosa (1910), en donde se recordaban los orígenes y el desarrollo vertiginoso que había experimentado el fútbol en Barcelona.

\subsection{ETAPA DE CONSOLIDACIÓN INSTITUCIONAL (1910-1919). EL FÚTBOL LLEGA A LOS COLEGIOS, AL EJÉRCITO Y A LAS CLASES MEDIAS. APARECE EL “VIRUS” DEL PROFESIONALISMO}

Como ya venía siendo reconocido en algunas escuelas de la Institución Libre de Enseñanza (ILE), el foot-ball gozaba de un gran interés pedagógico como medio de educación física. Así lo especificaba Godofredo Escribano (1912), profesor de la Escuela Normal Central, o el profesor Max Bembo en el Colegio que dirigía en Sabadell (Alsina, 1982).

Superada la primera década del siglo XX, el fútbol infantil se estableció como el juego de moda entre los colegios más elitistas de las congregaciones religiosas de las principales ciudades. No obstante, en otras poblaciones más pequeñas y menos importantes, colegios privados y públicos organizaron equipos de fútbol y disputaron partidos amistosos. Sirva como ejemplo, en la provincia de Lérida, la primera identificación del fútbol escolar localizada para la Fiesta Mayor de Castellserà, en mayo de 1911, cuando los equipos de infantiles FBC Castellserà y FC Urgell disputaron un partido de foot-ball (Torrebadella, 2012ª).

En la redacción del Reglamento provisional de gimnasia para infantería del Ministerio de la Guerra (1911), ya quedaba prescrita la preparación física del soldado, que a través de la gimnástica sueca se completaba con los juegos deportivos, entre los que destacaba el "balompié". En 1914 la Academia de Infantería de Toledo tenía organizado un equipo de fútbol y disputaba partidos contra la Sociedad Madrid FC ante SS. MM. (V. G. C., 1914). En unos años, la afición del fútbol se extendió entre numerosas guarniciones militares. Ello condujo a que el comandante Eduardo Suárez Sousa emprendiese la organización de un Campeonato de Fútbol Militar, solamente para las guarniciones de Madrid, ofreciendo una copa de S. M. (S. de T., 1919a , 1919b). El éxito del Campeonato fue tal que se extendió por todos los regimientos de España, con la organización del primer Campeonato Deportivo Militar de España celebrado durante la primavera de 1919, con una inscripción de 46 regimientos (Condo, 1919; S. T., 1919).

Barba $\left(1912^{\mathrm{a}}\right)$ aportó una "Breve reseña histórica sobre algunas sociedades foot-ballistas españolas” en las que se citaban al Barcelona FC, el Catalá Sport Club, el España FC, el Español Club Deportivo, el Universitari Sporting Club, el Tarraco Club (Tarragona), el Sporting Club de Reus, y Sporting Club de Sabadell, la Gimnástica Española (Madrid), el Madrid FC, el Levante (Valencia), el Valencia FBC, el Hispania (Valencia) el Rat Penat (Valencia), el Sportnig Club de Murcia, el San Sebastián FBC, la Real Sociedad de San Sebastián, el Real Fortuna (Vigo), el Club del Ferrol, el Pontevedra Sportng Club, el Círculo Mercantil e Industrial (Avilés), el Biskaya Club (Bilbao), Real Club Coruña, Atlétic Club de 
Bilbao, Lucentum Foot Ball Club de Alicante, Español FBC (Madrid) y el Madrid FC. De algunas de estas entidades, Barba $\left(1912^{\mathrm{a}}\right)$ incorporó más datos que indican su nivel asociativo [Tabla, 1].

En esta época, Barcelona ya se identifica como el motor del deporte español. En 1912 surgieron en la ciudad catalana plataformas institucionales como el Sindicato de Periodistas Deportivos o la agrupación de Sociedades Deportivas de Barcelona, que incentivaron la propaganda deportiva y, en especial, el fútbol (Navarro, 1917; Pujadas y Santacana, 1995). También, como hemos adelantado en el apartado anterior, se constituyó la Federación Española de Clubs de Foot-ball, creada por iniciativa del FC Barcelona y las peticiones de Narciso Masferrer Sala (1867-1941) -el principal embajador del deporte en España- en El Mundo Deportivo (Mensa, 1909c). En Barcelona, la revista Los Deportes (1897-10) se encargó durante una década de seguir y fomentar la afición del deporte en toda España (Torrebadella, 2012b).

La emergente prensa en el País Vasco, como Vida Sportiva (1912: 1) de San Sebastián, se centraba preferentemente en el foot-ball, del que citaba ser el deporte "más extendido en España y cuyas noticias son las que más se leen por mayor número de personas y las que se comentan siempre con mayor interés". Desde las páginas de esta publicación, y ante la inoperatividad de la Federación Española de Foot-ball para organizar encuentros internaciones, se pedía a los clubes vascongados la organización de una selección que disputase competiciones contra otras selecciones, como ya lo estaba haciendo la Selección Catalana (Watsson, 1912).

Las continuas desavenencias entre los clubes y la Federación Española de Football (Petronio, 1912) conllevaron finalmente una escisión y la constitución en noviembre de 1912 de la Unión Española de Clubs de Foot-ball -constituida por varios equipos guipuzcoanos, catalanes y el Deportivo de la Coruña-, que en febrero 1913 fue recocida como Real Unión Española de Clubs de Foot-ball (1913). Durante varios años, cada entidad organizó sus propios campeonatos de España, hasta que en septiembre de 1913 se reunificaron para poder disputar encuentros internacionales y adherirse a la Federación Internacional de Foot-ball Amateur (Alonso, 1924; Masferrer, 1928; Soto, 1930).

Sin embargo, todavía no se había escrito ninguna monografía técnica que acercara la iniciación y los secretos del juego a los aficionados. Desde principios del siglo XX, la prensa fue incorporando algunos artículos técnicos, pero insuficientes para cubrir las necesidades de formación de los aficionados. En 1913, el profesor Marcelo Sanz (1913) ofrecía la información estadística por provincias de un total de 371 de asociaciones deportivas. En ese estudio destacaban las provincias de Barcelona, con 71 entidades y Madrid con 27, y se indicaba que la mayoría de las asociaciones se dedicaba especialmente al fútbol 
Tabla 1. Número de socios en entidades deportivas

\begin{tabular}{|c|c|}
\hline Entidades futbolísticas & Socios \\
\hline Bilbao Foot Ball Club (1896) & 137 \\
\hline Atlétic Club (Bilbao, 1898) & 250 \\
\hline FC Barcelona (1899) & 531 \\
\hline Madrid FC (1900) & 50 \\
\hline Biskaya Club (1901) & 340 \\
\hline Real Club Coruña (1901) & 700 \\
\hline Español FBC (Madrid, 1905) & 132 \\
\hline Valencia FBC (1906) & 150 \\
\hline Racing Club (Irun, 1908) & 250 \\
\hline Lucentum Foot-Ball Club de Alicante (1910) & 142 \\
\hline Totales & 2.682 \\
\hline
\end{tabular}

En esta época, la prensa deportiva ya se hacía eco de las cuestiones referidas a la profesionalización en los deportes, en especial del fútbol (R. C. M., 1913). Los escándalos de profesionalismo tomaban protagonismo en la figura de Manuel Carrasco, declarado como profesional por la Unión Española de Clubs de Football, porque pedía un sueldo a la Real Sociedad para formalizar su fichaje (Nuestras sociedades, 1913).

José Elías (1914: 19) incorporó en Foot-ball asociación un artículo titulado "El foot-ball como medio de educación física” con el que deseaba instruir al lector sobre las ventajas de este deporte para la formación integral de la persona. Concretamente, se refería a las "ventajas que han elevado el juego del foot-ball a la categoría de deporte mundial, pues puede casi afirmarse que se práctica, en más o menos grado, en todas las tierras civilizadas".

De igual modo, el maestro de educación primaria José Oses (1915) glosaba el modo de jugar al fútbol como un excelente medio de educación física, tal y como ya había difundido el pedagogo inglés, Thomas Arnold, entre sus alumnos. Sobre el juego en España, mencionaba que en las ciudades y en los pueblos apenas existía muchacho que no se hubiera apasionado por este deporte, gracias a las "elegantes colecciones de cromos que las fábricas de chocolates ponen en manos de los niños, dando a éstos un verdadero curso de foot-ball" (Oses, 1915: 65).

En Cataluña, el fútbol se extendía por la costa, pero también llegaba a los rincones más remotos, con la consecuente constitución de asociaciones como el F. C. Valira en La Seu d'Urgell en 1914 o el F. C. Tremp en 1915 (García-Castell, 1968). Si tomamos como un indicador de referencia la provincia de Lérida, se observa que de 1911 a 1919 se crearon 38 asociaciones futbolísticas, cifra muy reveladora de la incidencia que estaba alcanzando el fútbol popular en esa comunidad (Torrebadella, 2012 ${ }^{\mathrm{a}}$ ). 
Tras la primera década del siglo XX, el fútbol fue extendiéndose de forma progresiva y fue ocupando el protagonismo asociativo deportivo de las clases obreras y populares (Castro, 2012). En Madrid, en 1916, 21 de las 39 sociedades deportivas censadas pertenecían al fútbol (Gallego, 1916, 1917). El fútbol empezaba a ser, pues, un deporte de práctica popular (Navarro, 1917).

En esta época, la especialización deportiva no había tomado aún carta de naturaleza. El fútbol se practicaba como un deporte más en el saludable estilo de vida de los sportsmen. Para equilibrar el desarrollo corporal, había quien propagaba la gimnasia sueca como complemento o preparación física para las prácticas deportivas, especialmente el fútbol, o, como en el caso de Alberto Maluquer (1915), quien hermanaba el fútbol con el atletismo, tal y como estaban realizando algunos de los mejores foot-ballistas del momento.

En Barcelona también aparecieron las primeras revistas monográficas dedicadas al fútbol. El 27 de mayo de 1915 apareció el primer número de Football (1915-1919) -que en 1918 alcanzó los seis mil ejemplares semanales- y, más tarde Fútbol (1919-23), revistas que, como citan Pujadas y Santacana (1997: 39), aspiraban a tener una implantación a nivel de Estado. También apareció $L a$ Zancadilla (1920), efímera revista satírico-futbolera que iniciaría el periodismo deportivo de humor (Pujadas y Santacana, 1997).

En 1915, cuando Miguel de Unamuno (1915) abordaba la desnaturalización deportiva del foot-ball, indicando que se había rendido al exhibicionismo y al puro espectáculo, se creó el Colegio Catalán de Árbitros de Fútbol. Hasta entonces el fútbol estuvo arbitrado por aficionados, quienes la mayoría de las veces eran designados momentos antes de los encuentros (García-Castell, 1968; Navarro, 1917; Perís, 1928). A partir de esta fecha, se crearon otros colegios regionales promovidos por la Federación Española de Foot-ball como el Colegio de Árbitros de la Federación Regional de Centro, presidido por Carlos Dieste o el Colegio de Árbitros de la Federación Regional Vascongada, presidido por Eugenio Angoso.

En 1916, la Federación Catalana de Clubs de Foot-ball contaba con sesenta entidades afiliadas (Navarro, 1917). En estos años, el fútbol todavía se conceptuaba como un medio de educación física que se complementaba con la práctica física de otros deportes como el atletismo, el ciclismo, la natación o la gimnástica. Sin embargo, hacia finales de la segunda década se marcó el inicio de una trayectoria hacia la especialización. Asimismo, en Cataluña, el fútbol se iba considerando paulatinamente como deporte espectáculo:

Puede asegurarse que los partidos de foot-ball contra bandos extranjeros y nacionales y determinadas contiendas de concurso entre los clubs de la localidad, atraen a los campos de sport a una muchedumbre casi tan numerosa en ciertas ocasiones, como la que se reúne en las corridas de toros. Tal es la afición que existe en Cataluña por este exótico deporte. (Navarro, 1917: 148).

José Lapique Adrio, director del Correo Gallego, instigaba a los poderes públicos a iniciar diversas campañas divulgativas en pro de la educación física. 
Ante el abandono institucional de la cultura física, propuso la propagación de los ejercicios corporales al aire libre y destacó el foot-ball como el primero de los deportes que había que fomentar, con el objeto de "atraer adictos y por contarse ya con una no despreciable cifra de partidarios” (Lapique, 1917: 225).

En obras tan populares como El médico en casa, la Dra. Fanny (1918), pseudónimo del pedagogo Joan Bardina Castarà (Torrebadella, 2013), presentó el fútbol como un medio de regeneración y pedía su protección debido a sus beneficios individuales y sociales, en un momento en el que todavía el gobierno ni tan siquiera le había prestado atención:

Como ser futbolista está al alcance de todas las fortunas, porque requiere un gasto insignificante, lo que no ocurre con otros deportes, se han dedicado con ahínco muy loables las clases medias y populares, con dos ventajas positivas de índole social: una que contribuye a vigorizar la raza, y otra que sustrae del café, de la taberna y del tugurio a millares de individuos jóvenes. Por esto los gobernantes y los particulares deben hacer por que la afición al fútbol no decrezca, antes aumente continuamente en nuestro país. (Fanny, 1918: 185)

El padre Luis López (1918) reafirmaba el valor educativo e higiénico del fútbol en las Escuelas Pías. Sirva como ejemplo el proyecto deportivo de los escolapios de Tàrrega, de donde salió en 1914 el primer team leridano que se dio de alta en la Federación Catalana de Fútbol (Torrebadella, 2011b; Torrebadella, 2012a). En esta época, podemos afirmar que prácticamente todas las escuelas masculinas de congregaciones católicas de España -escolapios, salesianos, jesuitas, maristas, etc.-, antes de llegar a los años veinte, ya habían construido sus propios campos de fútbol y organizado varios teams.

En 1919, año en el que terminó la Gran Guerra, la cantera del fútbol español ya estaba preparada bajo las pautas propagandísticas del discurso ideológico regeneracionista, oculto en los programas de educación física escolares (Torrebadella, 2014).

Al finalizar la segunda década del siglo XX, el fútbol ya había alcanzado cotas de popularidad que extendían su práctica entre las clases obreras, los cuarteles militares y los escolares (Bahamonde, 2011). Como citaba Isidro Corbinos (1919: 3), la neutralidad en la Gran Guerra supuso una oportunidad desaprovechada para elevar el nivel del deporte español. Sin embargo, el fútbol era considerado como el único deporte que había "alcanzado un brillante desarrollo" (Virior, 1919: 14).

En especial, el fútbol posibilitó la extensión del deporte, que originariamente había nacido en las élites de la burguesía y aristocracia de ciudades como Barcelona, Madrid, Bilbao o Sevilla, a otros ámbitos de participación más populares como el escolar, el movimiento obrero y el ejército. De igual modo que sucedió en Gran Bretaña, a partir de la década de 1880, el fútbol en España experimentó, treinta años más tarde, un proceso de proletarización y cimentó una subcultura deportiva, esencialmente ritualizada y simbólica: la cultura futbolística (Hobsbawm, 1986). A medida que el fútbol alcanzaba mayor popularidad, la alta 
burguesía y la aristocracia se distanciaron de su práctica, conceptuándola como una manifestación propia del "populacho" (Bahamonde, 2011: 93-94).

Asimismo, las rivalidades regionalistas y nacionalistas iniciaron el carácter político que pronto selló la trayectoria del deporte español (Díaz, 2000). Un claro ejemplo lo hallamos cuando el periodista Luís Aymamí (1919), en la coyuntura de las reivindicaciones autonomistas de Cataluña, declaraba que las confrontaciones deportivas de los equipos de fútbol catalanes tenían un fondo de sentimiento patriótico: "Per Catalunya i per a Catalunya": "Tots els catalans desitgem que el Campió de Catalunya conquereixi la suprema ictoria. A la lluita doncs, simpàtics jugadors blaugranats. Penseu que no és sols el nom del F. C. Barcelona el qual aneu a defensar. És el de Catalunya" (Aymamí, 1919: 1-2).

El "virus" de la profesionalización apareció hacia finales de esta etapa y desató las primeras críticas en el entorno de los clubes catalanes (Lemer, 1918). Estas preocupaciones engendraron la idea de crear un Sindicato de Deportistas (Torrens, 1919) y el de proteger el fútbol más amateur con la creación de una "Unión de Clubs de foot-ball no federados”, que acogiera a la prolífica expansión del fútbol regional y de clubes humildes (Bembo, 1918 ${ }^{\mathrm{a}}, 1918^{\mathrm{b}}$ ).

Álvaro Aguilar (1919: 23), presidente del Atletic-Club, diagnosticó la amenaza del profesionalismo, que se adelantaba a la primera crisis del fútbol, indicando que había entrado en una decadencia "debida al gran desarrollo del profesionalismo, más o menos encubierto. El profesionalismo individual ha pasado generalmente a ser profesionalismo de sociedades. Nada que hacer si no se combate a muerte el gran enemigo del deporte".

Otro aspecto que preocupaba fue la desmesurada violencia que adquirió el fútbol, no solo entre los propios jugadores, sino también entre el público aficionado y los directivos. La revista Foot-ball se lamentaba, a este respecto, de los antagonismos y del "fanatismo de las masas, que se traducen en espectáculos deplorables", puesto que los clubes que "debieran ser rivales solo en el terreno, resultan enemigos en las juntas y en las calles” (Del momento, 1918: 2).

Durante este periodo, el fútbol fue afianzando su espacio en las secciones deportivas de los principales periódicos de noticias como La Vanguardia o ABC (Simón, 2012). Dada la importancia que adquiría la crónica futbolística, el árbitro Francisco Brú (1885-1962) advertía de la necesidad de establecer un manual de estilo del lenguaje futbolístico para uso de los periodistas (Brú, 1918; Torrebadella y Nomdedeu, 2013).

A partir de la década de 1920, el fútbol trazó una trayectoria muy diferente a la descrita. El fin de la I Guerra Mundial abrió nuevos horizontes hacia la internacionalización del fútbol local y nacional. El primer éxito llegó de inmediato a cargo de la selección española, la llamada "furia española”, que dirigía el entrenador Francisco Brú, y su inesperada medalla de plata en los Juegos Olímpicos de Amberes de 1920 (Castro, 1920; Deportista, 1924). Desde entonces, el fútbol experimentó un auge asociativo y una popularización definitiva (Polo, 
1986, 95), que lo ha situado como el espectáculo y el deporte de masas más importante que hoy existe en España (Pujadas y Santacana, 2001).

\section{RESULTADOS Y DISCUSIÓN}

La primera publicación importante del deporte español fue el Manual de Sport de Antonio Viada (1903), redactor de "Notas de sport" de la Ilustración Española y Americana (Torrebadella y Olivera, 2012), y puede afirmarse que prácticamente hasta la segunda década del siglo XX fue el único referente del deporte moderno publicado en España. En esta primera enciclopedia del deporte, el foot-ball ya fue presentado como un higiénico sport que ponía "en juego todas las cualidades del atleta, las físicas, las morales y las intelectuales” (Viada, 1903: 485).

Otra obra técnica que incorporó un capítulo dedicado al foot-ball fue Sports atléticos (ca. 1910: 159-213) de Ernest Weber, redactor del periódico L'Auto de París. Esta obra editada originalmente en 1905 por la Librería de los Hermanos Garnier de París fue también muy conocida en España entre los sportsmen de la época, puesto que contó con al menos nueve ediciones -la mayoría si fecha de publicación-, en cuyo título fue substituida la palabra sports por deportes (Weber, 1926).

En 1909, cuando se constituyó la Federación Española de Foot-ball, todavía no existía un manual o monográfico técnica de fútbol. Hacia 1910 la Editorial IberoAmericana de Barcelona presentó una adaptación del Football (Association), que publicaron en Francia Tunmer y Fraysse (1897), y que en España se incorporó en un tratado de la colección "Los sports de moda" con el título Foot-ball, según los consejos de M. M. Tunmer y Fraysse, Waterpolo. Jiu-Jitsu por el barón Rene de Montespin a partir de la $3^{\mathrm{a}}$ edición revisada y aumentada original en francés de 1908. La obra se ocupa de la preparación física y el entrenamiento, de la táctica y la técnica del juego, y ofrece consejos a los jugadores. Destacamos uno de estos consejos que se encaminaba a reducir el excesivo grado de violencia que caracterizaba el juego de la época: "El foot-ball es un juego violento, y esto precisamente es lo que sugestiona a la juventud, siempre amante del peligro, y por esto precisamente los jugadores deben evitar todo acto que resulte intencionadamente brutal” (Tunmer y Fraysse, $c a$. 1910: 41). 
Figura 1. Obras de sport que incorporaron el foot-ball: Viada (193), Tunmer y Fraysse (ca. 1910), Weber (ca. 1910) y Barba $\left(1912^{\mathrm{a}}\right)$
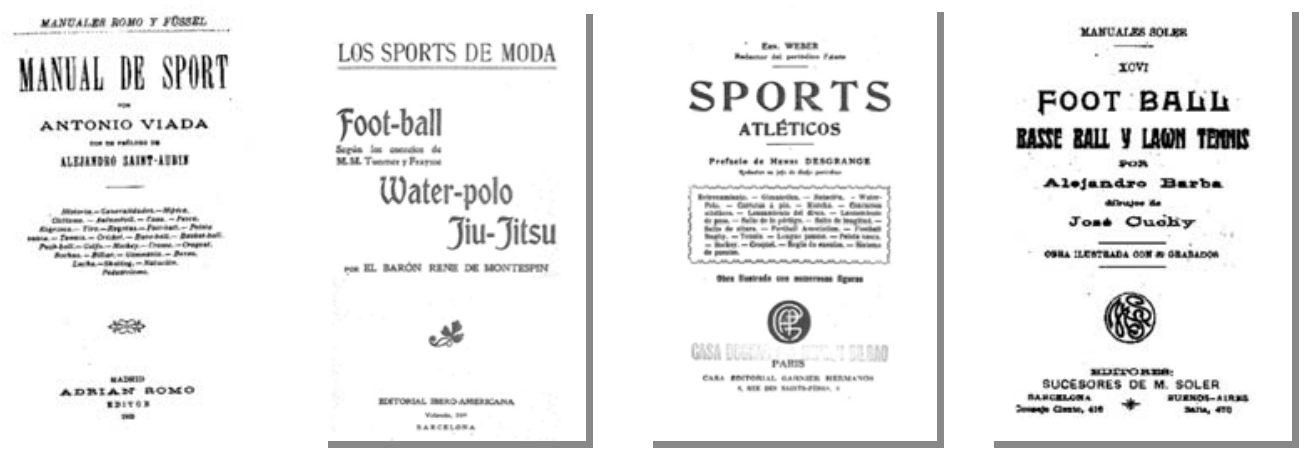

Durante la primera década, aparte de las obras que acabamos de citar, no existieron publicaciones técnicas importantes, salvo algunos reglamentos del juego, como los publicados por la Asociación de clubs de Foot-ball de Barcelona, el primer Reglamento de foot-ball publicado en España de 1902 y el publicado por Lloret en 1906, o el editado por la Federación Española de Clubs de Foot-ball en 1910.

Inicialmente, las primeras publicaciones deportivas tenían un claro objetivo: divulgar e implantar la afición deportiva en España. Era lógico que, si se pretendía ilustrar la deportividad de los españoles, hubiera quien se implicara en divulgar tratados deportivos en la propia lengua. Así lo admitía Alejandro Barba (1912 ${ }^{\mathrm{a}}$ : 56): “Opino que la vulgarización de los deportes que apenas si han franqueado las divisorias que les separaban de nuestra nacionalidad, es uno de los asuntos que enérgicamente ha de acometerse sin vacilaciones ni desmayos”. En otra obra, este mismo autor añadía:

La bibliografía deportiva es casi extranjera, y, por consiguiente, un número relativamente reducido de lectores españoles disfrutaban del privilegio de la enseñanza en tales fuentes de ilustración. Por este motivo, entiendo que es un deber social, y si se quiere hasta patriótico, difundir esta clase de enseñanzas entre los que hablan el idioma de Cervantes. (Barba, 1912b: 7).

Alejandro Barba $\left(1912^{a}\right)$ publicó el Foot Ball, Basse Ball y Lawn Tennis en la extraordinaria y voluminosa Biblioteca de "Manuales Soler", extensamente difundida por España y por los países latinoamericanos. El autor aportó esta obra para cubrir la escasa literatura deportiva autóctona, contribuir a vulgarizar la afición deportiva entre los españoles y coadyuvar a la "gran empresa de nuestra regeneración” (Barba, 1912ª: 5).

En 1913, en Barcelona, la editorial “Ciencias y Letras” publicaba en una “Biblioteca Deportiva” el Novísimo tratado de Foot-ball de Georges Graham. La obra de Graham podría ser considerada como la primera monografía técnica publicada en España, tratando únicamente el deporte del fútbol (Torrebadella, 
2009, 2011a). A través del sumario de la obra puede observarse su carácter especializado: Primera parte. Generalidades: I.- Historia del foot-ball en la antigüedad y en la Edad Moderna.- Rugby y Asociación.- II. Utilidad del foot-ball considerado como un elemento de educación física y moral.- III. Indumentaria e higiene.- IV. Entrenamiento del jugador.- Ejercicios de gimnasia y desarrollo de la fuerza muscular.- Ejercicios técnicos.- V. Advertencias y del material que exige el foot-ball. Segunda parte. Técnica de juego: I.- Reglamento oficial.- II. Del capitán del equipo.- III. Del árbitro; resolución práctica de casos dudosos.- IV. De los jugadores.- Los delanteros.- Los Medios.- Los defensas o zagueros.- Los porteros.V. Táctica del juego.

En 1914 José Elías Juncosa (1880-1944), redactor deportivo de La Veu de Catalunya (Torrebadella y Olivera, 2012), presentó la primera obra monográfica del fútbol español, Football asociación. Elías se declaró defensor a ultranza del modelo educativo que ofrecía el deporte inglés y abogó por la incorporación de las virtudes pedagógicas desplegadas por Thomas Arnold (Elías, 1916, 1917b). Asimismo, como se ha indicado en la literatura especializada sobre el tema que nos ocupa, José Elías siguió y propagó las ideas pedagógicas de Pierre de Coubertin (Balius, 1982; Elías, 1992; Marín, 1997).

Figura 2. Las primeras obras monográficas del fútbol publicadas en España estaban enmarcadas en colecciones deportivas que tenían por objeto la promoción del deporte: Graham (1913), Elías (1914), Gibert (1918).
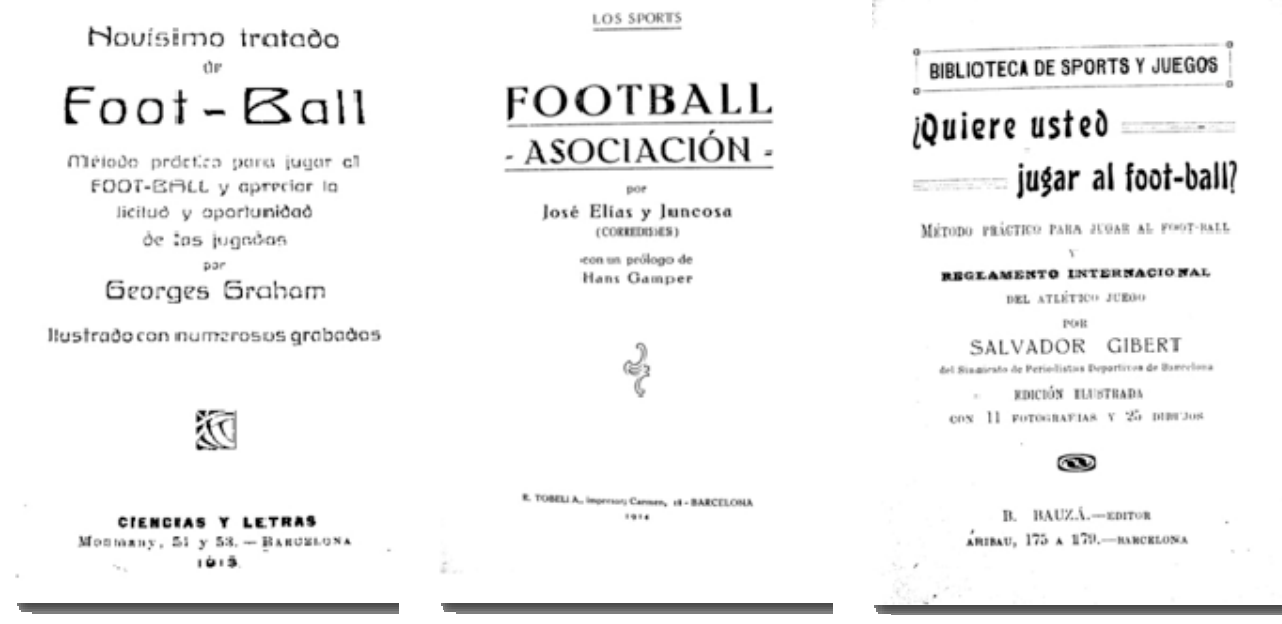
El rápido crecimiento asociativo debió incentivar a la prestigiosa editorial pedagógica Bastinos para publicar también obras como El foot-ball. Lo que debe saber el árbitro. Lo que deben saber los jugadores. Lo que debe saber el público (Sully, 1916).

En Foot-ball. Año y medio de vida sportiva, “Trilobites” (1917), pseudónimo del sportsman Adolfo Vázquez, presentaba las memorias futbolísticas vividas por el autor en las Islas Baleares y de los partidos disputados por el Alfonso XIII C. F. De esta obra, El Mundo Deportivo citaba que se trataba de una "Bella historia" (Bella historia, 1917).

Salvador Gibert (1918), del Sindicato de Periodistas de Barcelona, presentó ¿Quiere V. jugar al Foot-Ball? Método práctico para jugar al Foot-ball y Reglamento Internacional del atlético. En el sumario se indica: Cuatro palabras acerca del origen del Foot-ball.- ¿Qué es el juego del Foot-ball?.- El campo de juego: La pelota, los jugadores, el equipo.-. Higiene del jugador: su vestido, su calzado.- De las perfectas posiciones en el Foot-ball.- El capitán del equipo.- De la conducta a seguir por el jugador en el campo.- Del público. El arte de ver jugar el Foot-ball.- Reglamento oficial de foot-ball.- Nociones sobre el Rugby.

En esta época la colección "Sports y juegos" de la editorial Bauza de Barcelona incorporaba dos títulos más: Para ser buen jugador de foot-ball (ca. 1919) y, otra obra, que pudiera ser de José Llovera (ca. 1919), Modo de entrenarse en el FootBall, ambas obras referenciadas en la contraportada de Sola (1921) y La Unión Ilustrada (1923) ${ }^{4}$.

El progresivo crecimiento del fútbol llevó a Román Sánchez Arias, popular periodista deportivo del $A B C$ conocido con el pseudónimo de Rubryk (1919), a publicar De futbol ¿Cómo debe ser un buen árbitro? Consejos de un aficionado. Destacamos esta obra como la primera obra técnica en la formación profesional del arbitraje del fútbol publicada en España. Asimismo, resaltamos que Rubryk se descubrió como uno de los principales refractarios del fútbol escolar en los años veinte (Torrebadella, 2012d).

Finalizamos este período con la obra de Ángel Femenia (ca. 1920), El jugador de foot-ball: Libro práctico para jugar, dirigir y presenciar partidos de football association, datos sobre historia, indicaciones y consejos, reglas, higiene de los jugadores, accidentes, vocabulario y un reglamento oficial. El autor se atrevió a declarar que su libro aventajaba a cuantos libros de foot-ball españoles se habían publicado "por la variedad y cantidad de materias y que no cede a ninguno en el propósito de ser curioso y práctico" (Femenia, ca, 1920: 8). Destacamos que Femenia no aceptó ninguno de los neologismos con los que se pretendió españolizar el foot-ball, como el vocablo "futbol" del que decía "nos parece bárbaro y absurdo.

\footnotetext{
${ }^{3}$ Lamentablemente no hemos podido localizar ningún ejemplar de esta obra.

${ }^{4}$ Lamentablemente no hemos podido localizar las citadas obras.
} 
Es escribir caprichosamente una palabra extranjera, quitándole lo que tiene de inglesa y sin lograr darle vida y alma española” (Femenia, ca, 1920: 10). Una razonada divagación lingüística y terminológica sirvió al autor para justificar "la frecuencia con que este libro empleamos las palabras Foot-ball y otros necesarios barbarismos, aún conociendo mucho de lo que se ha escrito, con más o menos ingenio y autoridad, para condenar estos convenientes neologismos, sin equivalencia en castellano" (Femenia, ca. 1920, 13). Por esta razón Femenia no dudó en facilitar al lector un vocabulario del foot-ball: léxico inglés-español de 43 voces.

\section{CONCLUSIÓN}

Antes de llegar a los años veinte del siglo pasado, las obras instructivas relativas al fútbol o las monografías técnicas, a excepción de algunos sencillos reglamentos, apenas superaron la media docena. La literatura técnica futbolística penetró con cierto retraso, si tenemos en consideración lo avanzado que estaba el fútbol inglés en este periodo. Los primeros libros que incorporaron contenidos de fútbol fueron publicaciones deportivas de tipo general (Barba 1912a; Tunmer y Fraysse, $c a$. 1910; Viada, 1903; Weber, $c a$. 1910) y la primera obra monográfica presentada en España fue una traducción extranjera publicada en Barcelona, Novisimo tratado de Foot-ball de Georges Graham (1913). Un año más tarde se presentó, también en Barcelona, la primera obra monográfica de fútbol elaborada originalmente en español, Football asociación del sportsman José Elías (1914).

Los primeros manuales técnicos publicados tuvieron un carácter simplista. El contenido cubría la descripción básica del juego, su reglamentación y, en ocasiones, algunos elementos de la técnica futbolística (Barba, 1912ª ; Elías, 1914; Gibert, 1918; Graham, 1913; Sully, 1916). Aparte, localizamos otras obras al servicio técnico del arbitraje (Rubryk, 1919) y de carácter histórico estadístico (Trilobites, 1917).

Los libros apenas alcanzaban las cien páginas y, además, solían incluir algunas hojas publicitarias intercaladas en el texto o al final del mismo, gracias a las cuales se trataba de costear los gastos de la edición. La falta de una literatura técnica de calidad fue criticada, así como también la débil producción editorial, que prácticamente se concentró en Barcelona y en los profesionales del periodismo deportivo. El liderazgo territorial de Cataluña y la poderosa imprenta editorial y periodística de Barcelona fue una de las principales aportaciones a la bibliografía deportiva del fútbol.

Puede afirmarse que estas primeras obras cumplieron una función propagandística. Sin embargo, las monografías del fútbol fueron los libros deportivos más divulgados de principios del siglo XX y ya anunciaban el pronto éxito popular que iba a protagonizar el fútbol como espectáculo y deporte de masas.

Esta escasa bibliografía, aunque criticada por su simplicidad técnica, representó una ineludible referencia para conocer y desarrollar los fundamentos del juego 
entre los primeros aficionados o neófitos que desearon iniciarse en el popular deporte inglés. Asimismo, el fútbol generó la bibliografía más importante del movimiento gimnástico-deportivo de principios del siglo XX; una bibliografía que hoy nos ayuda a interpretar el desarrollo del fútbol español.

A partir de las fuentes documentales consultadas, no hemos podido hallar algunos de los ejemplares aquí citados. Esta situación que evidencia la pérdida documental sobre este tipo de obras, pone en alerta la necesidad de seguir precisando búsquedas de todo tipo con objeto de completar el repertorio bibliográfico, en este caso del fútbol en España.

Deseamos destacar finalmente como afirmaba Blanco $(1927,15)$, que a partir de un "trabajo preliminar de la Bibliografía metódica, cualquier persona de capacidad puede adquirir pronta la erudición necesaria sobre una materia”.

\section{REFERENCIAS BIBLIGRÁFICAS}

AGUILAR, Álvaro (1919), en “Deportes y atletismo”, en La Educación Física, no 6, p. 23.

ALMEIDA, Antonio S. (2006). Británicos, deporte y burguesía en una ciudad atlántica (Las Palmas de Gran Canarias, 1800-1914). Las Palmas: Universidad y Ayuntamiento de las Palmas de Gran Canarias.

ALONSO, Francisco (1924). Fútbol. Madrid: Biblioteca de deportes Calpe.

ALSINA, Joan (1982). 1913 - L'assaig pedagògic de Max Bembo a Sabadell. Sabadell: Fundació Bosch i Cardellach.

ASOCIACIÓN DE CLUBS DE FOOT-BALL DE BARCELONA (1903, 11 de octubre). Estatutos de la Asociación de clubs de Foot-ball. Los Deportes, p. 645-646.

- (1902). Reglamento de foot-ball / adoptado por la por la Asociación Clubs Foot-ball. Barcelona, s.e.

AYMAMÍ, Lluís (1919). "Per Catalunya i per a Catalunya”, en Catalunya Sportiva, $\mathrm{n}^{\circ} 121$, pp. 1-2.

BAHAMONDE, Ángel (2011). "La escalada del deporte en España en los orígenes de la sociedad de masas, 1900-1936”, en Attetas y ciudadanos. Historia social del deporte en España, 1870-2010. Madrid: Alianza Editorial, pp. 89-123.

- (2002). El Real Madrid en la historia de España. Madrid: Taurus.

BALIUS, Ramón (1982). “Josep Elías Juncosa”, en Apunts d' Educació Física i Medicina Esportiva, n ${ }^{\circ}$ 7, pp. 209-216.

BÁLMONT, Antonio (2009). 1884-1899: El origen del Decano del Fútbol "Huelva Recreation Club". Madrid: Bubok Publishing, S. L.

- (2007). La verdad sobre el fútbol sevillano entre 1890 y 1893. Aclaraciones a los historiadores del Sevilla F.C. Huelva. Madrid: Onuba. 
BARBA, Alejandro (ca. 1912a). Football, basse ball y lawn tennis. Barcelona: Ed. Sucesores de M. Soler.

- Alejandro (ca. 1912b). El boxeo y la esgrima de bastón. Barcelona: Ed. Sucesores de M. Soler.

"Bella historia" (1917, 20 de noviembre). El Mundo Deportivo, p. 1.

BEMBO, Max (1918a, 15 de agosto). “Carta abierta ¿Fuera posible la Unión”, en Foot-ball, p. 3.

- Max (1918b, 29 de agosto). "Mas sobre la proyectada Unión de Clubs de foot-ball no federados", en Foot-ball, pp. 4-5.

BLANCO, Rufino (1927). Bibliografia general de la educación física. Madrid: Hernando.

BRÚ, Francisco (1918, 7 de marzo). “El balompié y sus voces”,en Foot-ball, pp. 4-6.

“Campeonato Infantil” (1910, 7 de abril), en El Mundo Deportivo, p. 4.

CASTILLO, Julio del (1909). La educación fisica del soldado. Guadalajara: Imp. del Colegio de Huérfanos de Guerra.

CASTRO, Juan (2012). Orígenes del fútbol sevillano. La olvidada memoria británica. Madrid: Punto Rojo Libros.

CASTRO, Manuel de (1920). El foot-ball Olímpico. Vigo: El Faro de Vigo.

CASTRO, Vicente de (1904, 1 de marzo). "Foot-ball. Faltas y golpes Penados". Gran Vida, pp. 9-13.

CONDO, Augusto (1919). "El Primer Campeonato militar de foot-ball en Madrid", en La Educación Física, 5, 18.

CORBINOS, Isidro (1919, 22 de enero). "España ¿ingresará en la futura Sociedad de naciones deportivas?”. El Sport, pp. 3-4.

CORRESPONSAL (1908, 31 de mayo). "Desde Vigo. Foot-ball”, en Los Deportes, pp. 244-245.

"Del momento" (1918, 4 de enero), en Foot-ball, p. 2.

DEPORTISTA, Juan [Albert Martín Fernández] (1924). La furia española. Madrid, Imp. Renacimiento.

DÍAZ, Javier (2000). "Los nacionalistas van al fútbol. Deporte, ideología y periodismo en los años 20 y 30". ZER Revista de Estudios de Comunicación, ${ }^{\circ}$ 9, pp. 357-394.

DOMÍNGUEZ, Andrés (2009). Historia social do deporte en Galicia. Cultura deportiva e modernidade, 1850-1920. Vigo, Editorial Galaxia.

El Campeonato de Foot-Ball de Andalucía y Extremadura (1910, 31 de enero). Los Deportes, p. 21.

ELÍAS, José (1917a). Jocs de pilota. Noticia i regles. Barcelona: Ed. Consell de Pedagogia de la Diputació de Barcelona, Imp. Catalonia.

- (1917b). “Pedagogia esportiva (acabament)”. Quadenrs d'Estudi, no 4, pp. 307-313.

- (1916). "Pedagogia esportiva”. Quadenrs d'Estudi, nº 1, pp. 41-47.

- (1914). Football asociación. Barcelona: Imp. R. Tobeña. 
- (1910, 15 de marzo). "El foot-ball en Barcelona”. Los Deportes, pp. 69-74.

ELÍAS, Ramón (1992). Josep Elías i Juncosa "Corredisses", un precursor de l'olimpisme català. Barcelona, Generalitat de Catalunya - Departament de la Presidència, Secretaria General de l'Esport.

ESCRIBANO, Godofredo (1912). Ejercicios corporales. Madrid: Imp. de "La Enseñanza".

FANNY (1918). El médico en casa: tratado de higiene y de medicina popular, para uso de los padres de familia. Barcelona: Sociedad General de Publicaciones.

FEDERACIÓN ESPAÑOLA DE CLUBS DE FOOT-BALL (1910). Estatutos de la Federación Española de Clubs de Foot-ball: reglamento y disposiciones generales para la celebración de los partidos de foot-ball. Madrid: Imp. de Layunta y Compañía.

FEDERACIÓN GIMNÁSTICA ESPAÑOLA (1902, 2 de febrero). "Concurso organizado por la Federación Gimnástica española”, en Los Deportes, pp. 70-71.

FEMENIA, Á. (ca. 1920). El jugador de foot-ball: Libro práctico para jugar, dirigir y presenciar partidos de football association. Barcelona: Ed. Cooper.

"Foot-ball” (1903, 15 de julio). Nuevo Mundo, p. 22.

“Foot-ball” (1906, 13 de septiembre). El Mundo Deportivo, p. 5.

“Foot-ball. Campeonato de Madrid” (1906, 1 de diciembre). Gran Vida, pp. 12.

"Foot-ball. El arte de defender la meta" (1903, 1 de diciembre). Gran Vida, pp. 15-18.

GALLEGO, V. (1916, 1 de diciembre). "Madrid Deportivo”. Gran Vida, pp. 322-326.

GALLEGO, V. (1917, 1 de enero). "Madrid Deportivo". Gran Vida, pp. 17-22.

GAMPER, J. (1914). "Prólogo", en Football asociación. Barcelona: Imp. R. Tobeña, pp. 9-18.

GARCÍA-CASTELL, Joan (1968). Historia del futbol català. Barcelona: Aymà.

GIBERT, Salvador (1918). ¿Quiere V. jugar al Foot-Ball?. Barcelona: Ediciones Bauza.

GÓMEZ, J. (1914, 1 de marzo). "El primer equipo de futbol de la S. G. E.”. Gran Vida, pp. 89-90.

GRAHAM, G. (1913). Novísimo tratado de Foot-ball. Método práctico para jugar y apreciar la licitud y oportunidad de las jugadas. Barcelona: Ciencias y Letras.

HOBSBAWM, Eric J. (1986). La invención de la tradición. Barcelona: Crítica.

J. D. V. (1910, 15 de mayo). "Una carta. El Sport en el ejército". Los Deportes, 542, LXXII (Suplemento)

L. Z. (1902, 3 de noviembre). "Foot-ball”. La Correspondencia de España, p. 2.

La Unión Ilustrada (1923, 29 de abril). "Para los deportistas. Los libros de sport y juegos”. La Unión Ilustrada, p. 40.

LAGARDERA, Francisco (1996). "Notas para una historia social del deporte en España”. Historia de la Educación, no 14-15, pp. 151-172.

- (1992). "De la aristócrata gimnástica al deporte de masas: un siglo de deporte en España”. Revista Sistema, no 110-111, pp. 9-93. 
- (1990). Una interpretación de la cultura en torno a los orígenes del deporte contemporáneo en Cataluña. Barcelona: Universidad de Barcelona.

LAPIQUE, J. (1917). "Estudio de los ejercicios corporales que deberían fomentarse en las costumbres para el mejoramiento de la raza desde el punto de vista fisiológico; medios de popularizarlos”, en Obras premiadas en el Certamen Científico Sociológico: celebrado el 27 de mayo de 1916: El Ferrol: Imp. y Est. "El Correo Gallego”, pp. 219-231.

LEMER, A. (1918, 21 de noviembre). "Hacia una verdadera regeneración del football”. Foot-ball, pp. 6-7.

LLORET, Isidro (1906). Asociación de clubs de Foot-ball de Barcelona. Reglamento de juego. Barcelona: Los Deportes.

LLOVERA, José (ca. 1919). Reglamento del fútbol asociación. Modo de entrenarse al fútbol. Barcelona, Ed. B. Bauza.

LÓPEZ, L. (1918, 3 de enero). "El deporte futbolístico en las Escuelas Pías". Madrid-Sport, pp. 41-42.

LOZANO, Luis (1905, 30 de julio). “Notas de Sport”. El Liberal, p. 3.

M. (1907, 15 de junio). Foot-ball. Ilustración Militar. Ejército y Marina, p. 220.

MALUQUER, Alberto (1915, 17 de abril), en "El foot-ball y el atletismo". Arte \& Sport, p. 26-27.

MARÍN, E. (1997). "De la gimnàstica a l'esport: La pedagogia esportiva de Josep Elías i Juncosa”, en La formació inicial i permanent dels mestres, Actes de la XIII Jornades d'Història de l'Educació als Països Catalans. Vic, Ed. Eumo, pp. 413-419.

MASFERRER, Narciso (1928). "Episodios del año 1913”, en Llibre d'or del fútbol català. Barcelona: Edicions la "Monjoia”, pp. 498-499.

McFARLAND, Andrew (2013). "Founders, foundations and early identities: football's early growth in Barcelona”, en Soccer \& Society, vol. 14, n 1 , pp. 93-107. DOI: 10.1080/14660970.2013.767723.

- (2012). "Sport's growth in Barcelona and Catalonia from the 1890s to 1920: a case study”. Soccer \& Society, vol. 13, n 4, pp. 584-598. DOI: 10.1080/14660970.2012.677230.

- (2004). Creating a national passion: football, nationalism, and mass consumerism in modern Spain. Texas: University

MELÉNDEZ, A. (1903, 15 de abril). “El foot-ball en Madrid”. Nuevo Mundo, pp. 12-13.

MENSA, M. (1909a, 19 de agosto). "Federación española de Clubs de Foot-ball”, en El Mundo Deportivo, pp. 1-2.

MENSA, M. (1909b, 21 de octubre). "Federación Española de Clubs de Football”, en El Mundo Deportivo, pp. 1-2.

MENSA, M. (1909c, 15 de julio). "Foot-ball”. El Mundo Deportivo, p. 4.

MINISTERIO DE LA GUERRA (1911). Reglamento provisional de gimnasia para infantería. Madrid, Talleres del Depósito de la Guerra. 
MOSCOSO, David Jesús, y ALONSO, Víctor (2005). “Globalización y deporte. Una propuesta de investigación a través del fútbol en Canarias”. CCD. Cultura, Ciencia, Deporte, vol. 1, no 3, pp. 124-130. doi: 10.12800/ccd

NAVARRO, Emilio (1917). Álbum histórico de las sociedades deportivas de Barcelona. Barcelona: Imp. José Ortega.

"Nuestras sociedades" (1913, 15 de enero). Stadium, p. 46.

OSES, José (1915). Juegos de campo para niños. Los grandes y pequeños deportes al aire libre. Barcelona: Lib. de Perelló i Vergés.

OTERO, Luis Enrique (2003). Ocio y deporte en el nacimiento de la sociedad de masas. La socialización del deporte como práctica y espectáculo en la España del primer tercio de siglo. Cuadernos de Historia Contemporánea, ${ }^{\circ}$ 25, pp. 169-198.

"Partido de foot-ball en el Hipódromo" (1902, 23 de diciembre). La Época, p. 3.

PERÍS, Enrique (1928). Historial del Col-legi català d'Arbitres de Futbol. En B. Ribes Bancells (Ed.). Llibre d'or del fútbol català (pp. 21-23). Barcelona: Edicions la "Monjoia".

PETRONIO (1912, 15 de enero). Sobre la Federación Española de Clubs de Football. Vida Sportiva, pp. 1-2.

POLO, Jesús (1986). El fútbol español hasta la guerra civil, en Revista de Occidente, $\mathrm{n}^{\circ}$ 62-63, pp. 85-101.

PUJADAS, Xavier (coord.) (2011). Atletas y ciudadanos. Historia social del deporte en España, 1870-2010. Madrid: Alianza Editorial.

PUJADAS, Xavier y SANTACANA, Carles (2001). "La mercantilización del ocio deportivo en España. El caso del fútbol (1900-1928)”. Historia social, nº 47, pp. 147-168.

- (1997). L'esport és noticia. Història de la premsa esportiva a Catalunya (18801992). Barcelona, Col·legi de Periodístes de Catalunya.

- (1995). Història il-lustrada de l'esport a Catalunya -vol. I. Barcelona: Diputación de Barcelona - Ed. Columna.

R. C. M. (1913, 15 de enero). “Opiniones sobre el profesionalismo”. Stadium, pp. 29-31. REAL UNIÓN ESPAÑOLA DE CLUBS (1913, 20 de febrero). El Mundo Deportivo, p. 4.

RIBES, B. (Ed.) (1928). Llibre d'or del fútbol català. Barcelona: Edicions la "Monjoia".

RIVERO, A. (2003). Deporte y modernización: La actividad fisica como elemento de transformación social y cultural en España, 1910-1936. Madrid: Comunidad de Madrid. Consejería de Cultura y Deportes. Dirección General de Deportes.

RUBRYK (1919). De futbol. ¿Cómo debe ser un buen árbitro? Consejos de un aficionado. Madrid: A. Marzo.

S. de T. (1919, 24 de abril). "El foot-ball-militar”. Madrid-Sport, pp. 1-2.

S. de T. (1919, 5 de junio). "El foot-ball en Madrid. Final del Campeonato Militar”. Madrid-Sport, p. 4. 
SANCHÍS, José. P. (2010). La actividad gimnástica y deportiva en Sevilla durante el siglo XIX. Sevilla: Diputación Provincial de Sevilla.

SANZ, Marcelo (1913). Ensayo de una higiene deportiva o los deportes ante la higiene. Madrid, Imp. "La Correspondencia Militar".

SERRA, Alberto (1906a, 9 de febrero). "El foot-ball al alcance de todos, para uso de Colegios, Universidades, etc.” Los Deportes, pp. 151-152.

- (1906b, 17 de mayo). Foot-ball. De aquí y de allá. El Mundo deportivo, p. 3.

SIMÓN, Juan Antonio (2012). Conquistando a las masas: el impacto del deporte en la prensa española, 1900-1936. Revista de História do Esporte, vol. 5, no 1 , pp. 1-40. <http://www.sport.ifcs.ufrj.br/recorde/pdf/recordeV5N1_2012_17. pdf> [Consultado: 12/04/2014]

- (2011). La mercantilización del fútbol español en los años veinte: de la implantación del profesionalismo al nacimiento del campeonato nacional de liga. Esporte e Sociedade, $\mathrm{n}^{\circ}$ 18, pp. 1-30. < [http://www.ludopedio. com.br/rc/index.php/biblioteca/recurso/911]> [Consultado: 12/04/2014]

SIRERA, Carles (2008). Cuando el fútbol no era el rey: Los deportes en el espacio público en la ciudad de Valencia (1875-1909). Valencia: Universidad de Valencia.

SOLA, Mauricio (1921). ¿Quiere usted jugar al Lawn-Tennis?. Barcelona: Ediciones Bauza.

SOTO, Joaquín (1930). Historia del fútbol en España. Madrid: Compañía Iberoamericana de Publicaciones.

STEIMBERG, U. (1906a, 13 de septiembre). "Foot-ball. La Federación Española de Foot-ball”. El Mundo Deportivo, p. 5.

STEIMBERG, U. (1906b, 8 de noviembre). “Foot-ball”. El Mundo Deportivo, pp. 5-6. SULLY, R. (1916). El foot-ball. Lo que debe saber el árbitro. Lo que deben saber los jugadores. Lo que debe saber el público. Barcelona, Sucesores de Bastinos.

TORREBADELLA, Xavier (2014). "Regeneracionismo e impacto de la crisis de 1898 en la educación física y el deporte español”. Arbor, vol. 190, n 769 , pp. a173. doi: http://dx.doi.org/10.3989/arbor.2014.769n5012

- (2013). "La aportación bibliográfica de Joan Bardina a la educación física moderna (1911-1939)”. Cabás, no 9, pp. 1-22.

- (2012a). "El fútbol en Lleida: de los orígenes a la consolidación del fútbol comarcal (1910-1937)”. Cuadernos de Fútbol, revista oficial del CIHEFE, n ${ }^{\circ}$ 33, 34 y 36. <http://www.cihefe.es/cuadernosdefutbol/ author/xaviertorrebadella/ $>$ [Consultado: 12/04/2014]

- (2012b). "Las primeras revistas profesionales y científicas de la educación física española, 1882-1936”. Apunts. Educación Física y Deportes, n 109, pp. 11-25.

- (2012c). “Orígenes del fútbol en Barcelona (1892-1903)”. RICYDE. Revista Internacional de Ciencias del Deporte, $\mathrm{n}^{\circ}$ 27, pp. 80-102. Doi: 10.5232/ricyde2012.02706 
- (2012d). "El deporte contra la educación física. Un siglo de discusión pedagógica y doctrinal en la educación contemporánea”. Movimiento humano, 4, 73-98.

- (2011a). Repertorio bibliográfico inédito de la educación fisica y el deporte en España (1800-1939). Madrid, Fundación Universitaria Española.

- (2011b). "El boom de l'esport. Ideologia i Societat a l'esport targarí (19201937)". Urtx, $\mathrm{n}^{\circ} 25$, pp. 423-455.

- (2009). Contribución a la historia de la educación física en España. Estudio bio-bibliográfico en torno a la educación física y el deporte (1800-1939). Lleida, Universitat de Lleida: Departament d'Història de l'Art i Història Social. TORREBADELLA, Xavier y NOMDEDEU, Antoni (2014). "Repertorio bibliográfico en España (1900-1936). 121 obres para interpretar el impacto social del fútbol en la historia contemporánea”. Apunts. Educación Física y Deportes, $\mathrm{n}^{\mathrm{0}}$ 115, pp. 7-32. http://dx.doi.org/10.5672/apunts.20140983.cat.(2014/1).115.01

- (2013). "Futbol, foot-ball, balompié... Los orígenes de la adaptación del lenguaje anglosajón en el deporte español”, en RICYDE. Revista Internacional de Ciencias del Deporte, $\mathrm{n}^{\circ}$ 31, pp. 5-22. http://dx.doi.org/10.5232/ricyde2013.03101

TORREBADELLA, Xavier y OLIVERA, Javier (2012). "Las cien obras clave del repertorio bibliográfico español de la educación física y el deporte en su proceso de legitimación e institucionalización (1807-1938)". Revista General de Información y Documentación, $\mathrm{n}^{\circ}$ 22, pp. 119-168. http://dx.doi.org/10.5209/rev_RGID.2012.v22.39669

TORRENS, J. (1919, 26 de febrero). "Idea que prende.- Sindicato de Deportistas”. El Sport, pp. 3-4.

TRILOBITES (1917). Foot-ball. Año y medio de vida sportiva. Mallorca: Imp. de J. Tous.

TUNMER, N. G. et FRAYSSE, E. (1897). Football (Associatión). Paris: Armand Colin et Cie.

TUNMER, N. G. y FRAYSSE, E.; MONTESPIN, R. (ca. 1910). Foot-ball, según los consejos de M. M. Tunmer y Fraysse, Waterpolo. Jiu-Jitsu por el barón Rene de Montespin. Barcelona, Editorial Ibero-americana.

TURUZETA, Josu (2012). El Athletic Club. Origen de una Leyenda. Cuando el león era un cachorro. San Sebastián, Txertoa.

Un Sportman (1909, 21 de marzo). "De Sport. El foot-ball (o balón pie)”. Pamplona, p. 1.

UNAMUNO, M. de (1915, 15 de septiembre). "Deporte y Literatura”. Mundo Nuevo, p. 22.

URÍA, Jorge (2008a). "Imágenes de la masculinidad. El fútbol español en los años veinte”. Ayer, no 4. pp. 121-155. 
URÍA, Jorge (2008b). "Los deportes de masas en los años veinte. Fútbol, élites simbólicas e imágenes de modernidad en España”, en Salaün, S. y Etienvre, F. (eds.). La réception des cultures populaires et des cultures de masses en Espagne (XVIIIe-XXe siècle). Paris: Sorbonne Nouvelle-CREC, pp. 155-212. $<$ http://crec.univparis3.fr/actes/08\%20Uria.pdf> [Consulta: 20/04/2014]

V. G. C. (1914, 1 de marzo). "Partido Benéfico de futbol”. Gran Vida, 130, pp. 71-72.

VALSERRA, Fabricio (1944). Historia del deporte. Barcelona: Ed. Plus-Ultra.

VIADA, Antonio (1903). Manual de Sport. Madrid: Ed. Adrian Romo.

VIRIOR (1919, 8 de enero). "La próxima Olimpiada”. El Sport, pp. 13-14.

WATSSON (1912, 15 de enero). Vida Sportiva, pp. 2-3.

WEBER, Ern (1926). Deportes atléticos (Nueva edición corregida y aumentada).

París: Garnier Hermanos.

WEBER, Ern (ca. 1910). Sports atléticos. Paris, Editorial Garnier Hermanos.

"Ya tenemos Federación” (1909, 1 de octubre). Gran Vida, p. 28. 